\title{
Incorporating ember attack in bushfire risk assessment: a case study of the Ginninderry region
}

\author{
$\underline{\text { Melanie E. Roberts }}^{\text {ab }}$, Jason J. Sharples ${ }^{\mathrm{c}}$, Andrew A. Rawlinson ${ }^{\mathrm{a}}$ \\ ${ }^{\mathrm{a}}$ IBM Research - Australia \\ ${ }^{\mathrm{b}}$ University of Melbourne \\ ${ }^{\mathrm{c}}$ University of New South Wales Canberra \\ Email: j.sharples@adfa.edu.au
}

\begin{abstract}
Current methods for assessing the risk of bushfire to built structures are based on the assumption that the majority of structure loss is due to radiant heat exposure. However, data collected in the aftermath of recent destructive bushfires indicates that the impacts of radiant heat are insignificant compared to the impact of ember attack. Recent work by the Bureau of Meteorology has provided fundamental information on how embers are distributed by a convective plume. These ember distributions have subsequently been incorporated into a model that permits estimation of the likelihood of ember attack downwind from an active fire. In this paper we employ the ember load model to incorporate ember attack into bushfire risk assessment. In particular, we consider the case of the Ginninderry region, which is a tract of land currently subject to rezoning for urban development. The Ginninderry region is of interest because it is prone to dynamic modes of fire spread such as eruptive fire spread and vorticity-driven lateral spread, the latter of which is known to result in enhanced production of embers. The ember load model is used to assess the risk of the Ginninderry region to ember attack and compare the inferred risk to that informed by traditional risk assessment methods based on radiant heat thresholds.

The results of this case study indicated that risk of ember attack had a distinct directional signature, which is accounted for in the current approach to bushfire risk a ssessment. Moreover, the ember load model indicated that many areas at considerable risk of ember attack are further than $100 \mathrm{~m}$ from the urban edge. Such areas are not currently required to have any special resilience to embers. As such the results indicate that current methods of risk assessment could significantly underestimate the risk of house loss from bushfire, and that current requirements for construction standards should be extended further than $100 \mathrm{~m}$.

The present analysis contains a number of fairly crude assumptions, and so the results should be considered preliminary. Nevertheless, with some refinement, the ember load model could play an important role in more accurately informing bushfire risk assessment and provide a more quantitative basis for revising and improving the Australian standard for building in bushfire prone areas.
\end{abstract}

Keywords: Bushfire risk, Ember attack, Australian standard, dynamic fire spread 


\section{INTRODUCTION}

The losses caused by large bushfires over the last decade or so have prompted questions about the changing nature of bushfire events and how they impact densely populated areas. In particular, concern is centred on an apparent shift to a significantly more hazardous fire regime, characterised by increasing fire frequency and intensity associated with dynamic fire propagation, and the development of catastrophic 'firestorms'. Given the likely effects of climate change, the expectation is that large destructive fires will become more prevalent in the future (Sharples et al. 2016). This trend, combined with the increasing expansion of urban centres into wildland areas, will present an increasingly challenging problem to land managers and fire agencies.

In order to mitigate the impacts caused by large bushfires, a number of protective measures have been developed and implemented. These include: enhanced hazard reduction programs (e.g. prescribed burning), revised public warning systems, community engagement and eduction, enhancement of fire trail networks, and improved building design and construction guidelines combined with better informed urban planning. In particular, the Australian Standard for building in bushfire-prone areas AS3959 (Standards Australia, 2009) specifies requirements in order to improve the resilience of buildings against bushfire attack. In its current form, AS3959 is predicated on the assumptions that fires propagate at a quasi-steady rate of spread and that the main cause of house loss during bushfires is radiant heat exposure.

Specifically, AS3959 informs the design and construction of buildings in bushfire-prone areas through the concept of Bushfire Attack Level (BAL). In principle, BAL can be determined through application of the Standard to any site in the landscape, thereby providing the appropriate design and construction measures required to reduce the risk of bushfire igniting a building situated at the site. The calculation of BAL at a site relies on the following four main factors: Fire danger index, typically the McArthur Mark 5 FFDI; Vegetation type; Distance of the site from the classified vegetation; and Topographic slope on which the vegetation is situated. These quantities are combined to calculate the level of radiant heat exposure of the site. The level of radiant heat exposure is then classified into one of six BAL categories.

Recent research, however, has demonstrated that in the most devastating fires, which are responsible for the majority of damage (e.g. Canberra 2003, Black Saturday 2009), the main cause of house loss is ember attack (Leonard and Blanchi, 2005). While AS3959 does incorporate ember attack to a certain degree, it is based on the unsubstantiated assumption that ember intensity increases roughly in proportion to increases in radiant heat exposure. This may be approximately true in the case of short-range spotting, but the arrival of long-range embers at a built structure should not be expected to have any relationship with radiant heat exposure from flames. Indeed, there are a number of examples of intense ember attack occurring in the complete absence of flames - the embers originate from a fire some distance (perhaps several kilometres) upwind of the structure.

Research has also suggested that embers (both short- and long-range) are more efficiently generated and lofted in connection with extreme and dynamic fire behaviour. The convective intensity and high levels of turbulence associated with extreme fire behaviours (e.g. VLS (vorticity-driven lateral spread), fire eruptions) can more readily tear bark and other burning debris from trees and from the surface, and these firebrands can then be lofted high into the air and transported further downwind from the fire.

In this paper we draw on recent research to develop a model for ember attack, which acknowledges the enhanced effect that dynamic fire spread can have on ember intensity. The model accounts for both short-range and long-range spotting. Long-range spotting refers to embers entrained in the fire plume, and therefore lofted high above the fire before being dispersed by background winds, while short-range embers are those projected directly forward of the fire. The efficacy of the model is investigated using the Ginninderry region as a case study. The Ginninderry region lies to the west of the Australian Capital Territory, and is of interest for two reasons. Firstly, the region is currently subject to rezoning, to allow for urban development; ultimately the region is proposed to house around 30,000 people. As such, it is paramount to provide an accurate risk assessment of the region that better reflects the main bushfire attack mechanism responsible for house loss. Secondly, the landscape to the west and northwest of the region is highly prone to the occurrence of dynamic fire behaviour and extreme bushfire development. As such, the Ginninderry region provides a good opportunity to investigate how incorporation of ember attack and dynamic modes of fire propagation into bushfire risk assessment affects the way bushfire risk is perceived.

\section{Ember LOAd MOdel}

The ember risk of a property is a function of many factors of the built and natural environment, and is further influenced by actions taken to defend a property during a bushfire. Factors include local vegetation and 
topography, weather conditions, construction materials and layout of a property, and the availability and appropriateness of firefighting resources such as water supplies and personnel. These factors have been the focus of extensive research, including the generation, flight and ignition properties of embers (Tarifa et al., 1965; Albini, 1983; Woycheese et al., 1999; Manzello et al., 2006; Thurston et al., 2017), vulnerability of structures to ember attack (Cohen, 2001; Blanchi et al., 2006), and risks and benefits of active defence (Wilson, 1988; Haynes et al., 2010; McLennan et al., 2012).

Recent work by the Bureau of Meteorology has provided fundamental information on how embers are distributed by a convective plume. This information, together with observations of ember damage during post-fire analysis, enabled the development of a model to estimate the likelihood of ember attack downwind from an active fire (Roberts et al., 2017). Used predictively, this ember attack model provides a measure of the ember risk at a property, should a bushfire burn through local vegetation. The ember risk is defined as the potential ember load that a property could be subject to during a bushfire, due to local bushland such as national parks, state parks, and community green spaces, and the prevailing wind conditions. The model leverages public spatial datasets, which allows for the dynamic updating of the risk score across large geographic areas. The model however introduces a number of simplifications. The resilience or vulnerability of a property to ember attack is not considered; the results therefore only indicate the potential for impact, with higher scores requiring a more resilient property. Moreover, the reliance on vegetation information requires that the ember generation potential for forested areas is approximated. For a detailed description of the model and its implementation, we refer the reader to Roberts et al. (2017), and provide only a brief overview.

The distribution of embers originating from a unit area of forest is given by the probability density function (PDF) $\rho_{E}$, where the form of $\rho_{E}$ is dependent on the underlying mechanisms spreading the embers. Two mechanisms are considered in this model, short-range processes and long-range processes. While short-range embers can be lofted by thermals from the fire directly (Antheniena et al., 2006) and dispersed by background winds, long-range embers are entrained in the buoyant fire plume and are carried into the upper atmosphere before being dispersed. As suggested by the name, long-range embers can travel significantly further than short-range embers; during the Victorian Black Saturday bushfires spotting up to $30 \mathrm{~km}$ was observed (Cruz et al., 2012). Short-range embers occur on the order of hundreds of meters, while long-range embers occur on the order of kilometres. Although PDFs can be generated for each species individually, this would require detailed vegetation data, that is typically not available, as well as additional research into how embers from different plant species are dispersed.

The PDF $\rho_{E}$ gives the distribution of embers from a source, however our interest is in the potential collective impact of all vegetation in a region on an individual property. Convolution is used to sum across all vegetation in a region to obtain the cumulative ember load for a property. Thus the ember distribution due to a forest $\eta_{E F}$ is obtained by convolving the number density function (NDF) of the forest $\eta_{F}$ with the PDF for the embers $\rho_{E}$ :

$$
\begin{aligned}
\eta_{\mathrm{EF}}(x, y) & =\left(\rho_{\mathrm{E}} * \eta_{\mathrm{F}}\right)(x, y) \\
& =\int d x \int d y \rho_{\mathrm{E}}(x, y) \eta_{\mathrm{F}}\left(x_{1}-x, y_{1}-y\right)
\end{aligned}
$$

where the NDF of the forest $\eta_{F}$ describes the spatial distribution of the corrected fine fuel load, and $(x, y)$ is the location of the property of interest. Ideally, the NDF of the forest should reflect the propensity for the vegetation to generate embers, however here we approximate this value through the fine fuel load.

In this study we examine the effects of increased ember generation by the occurrence of dynamic fire spread. Specifically, we focus on the potential effects of VLS on ember generation. Sharples et al. (2012) derived the following model (characteristic function) to identify parts of the landscape prone to VLS occurrence:

$$
\chi(S, a, \theta)= \begin{cases}1 & S \geq 20^{\circ},|\theta-a| \leq 40^{\circ} \\ 0 & \text { otherwise }\end{cases}
$$

Here $S$ is the terrain slope, $\theta$ is the direction the wind is blowing and $a$ is the terrain aspect (the compass direction that the slope faces). The NDF of the forest is therefore given by

$$
\eta_{\mathrm{F}}=(\beta \chi+1) L
$$


where $L$ is the spatial distribution of the fine fuel load of the vegetation. $\beta$ represents the increase in ember load due to VLS. While there is evidence in linescans and photographs that indicates VLS occurrence does increase ember generation, it is not currently known by how much exactly. Hence, to examine the potential and relative effects of VLS on the overall ember load across a landscape we make the crude assumption that $\beta=1$, so that regions prone to VLS produce double the ember load otherwise produced by fine fuel loads.

As mentioned above, two mechanisms of ember spread are considered, short-range and long-range processes. Post-fire analysis of ember damage indicates that the density of embers decreases exponentially with distance from vegetation (Ellis, 2003; Tolhurst and Howlett, 2003). The PDF for short range embers is therefore

$$
\rho_{E_{\text {short }}}=\frac{\lambda^{2}}{\pi} \sqrt{\frac{\kappa}{u}} \exp \left(-\lambda \sqrt{\frac{\kappa}{u} x^{2}+y^{2}}\right),
$$

where $u$ is the $10 \mathrm{~m}$ wind speed $[\mathrm{m} / \mathrm{s}], x$ and $y$ are the distance in the downwind and transverse directions, and $\lambda$ and $\kappa$ are positive scaling parameters. The above equation assumes that the wind is travelling in the positive $x$-direction (westerly wind), and therefore a simple rotation is employed to account for variations in the wind direction. Eq. (4) represents embers travelling predominantly in the wind direction, with some transversal spread (controlled by $\kappa$ ). Ideally, the scaling parameters $\lambda$ and $\kappa$ are determined from observations or fitted to data, however here they have been assumed based on a rudimentary comparison with observed data from the Hastings Bushfire. Specifically, we assume $\lambda=0.05$ and $\kappa=0.1$.

The PDF for long-range processes is based on the findings of Thurston et al. (2014), who investigated the downwind and transverse spread of embers due to interactions between a plume updraft and background wind speeds, for wind speeds between 5 and $15 \mathrm{~m} / \mathrm{s}$. They found that, as with short-range processes, embers travelled predominantly in the wind direction with some transversal spread, where the degree of spread was a function of the wind speed. Higher wind speeds were observed to carry embers further from the origin and exhibited reduced spread compared with lower wind speeds. Based on the findings of Thurston et al. (2014) we use the following PDF to describe long-range ember dispersal:

$$
\rho_{E_{\text {long }}}(x, y)=\frac{1}{2 \pi N \sigma_{x} \frac{\sigma_{y}(x+2)}{\mu_{x}}} \exp \left[-\frac{1}{2}\left(\left(\frac{x-\mu_{x}}{\sigma_{x}}\right)^{2}+\left(\frac{y-\mu_{y}}{\frac{\sigma_{y}(x+2)}{\mu_{x}}}\right)^{2}\right)\right],
$$

where $\mu_{x}$ is the mean dispersal in the downwind $x$ direction, the mean dispersal in the transverse $y$ direction $\mu_{y}=0$, and $\sigma_{x}$ and $\sigma_{y}$ are the standard deviations of the dispersal in the $x$ and $y$ direction respectively. The normalisation constant $N$ is defined so that

$$
\int_{0}^{\infty} d x \int_{-\infty}^{\infty} d y \rho_{E_{\text {long }}}(x, y)=1 .
$$

The means and standard deviations used in this case are those given by Thurston et al. (2014). For a wind speed of $15 \mathrm{~m} / \mathrm{s}$, which is representative of days with fire danger rated at Severe or higher, this is $\mu_{x}=8.3$, $\sigma_{x}=3.29$, and $\sigma_{y}=0.16$.

The total ember risk at a property is the sum of the short-range and long-range risk. As an individual ember will be carried by either long-range or short-range processes, it is necessary to determine the proportion of potential embers at a site that will be subject to short- or long-range processes. We assume that the proportion of available embers that are entrained in the plume is a function of the background wind speed, specifically that the proportion increases quadratically with the fire intensity. As fire intensity has a third order relationship with the wind speed, it is therefore assumed that the proportion of embers entrained in the plume has a 5 th order relationship with the wind speed, and is given by $p=0.01+0.0004\left(u+10^{-4} u^{5}\right)$. One limitation of this approach is that differences in bark characteristics are not accounted for. This is a necessary assumption, given limitations in the current state of public vegetation data. The total ember risk is therefore

$$
\rho_{E}=\rho_{E_{\text {short }}}(1-p)+\rho_{E_{\mathrm{long}}} p
$$

The ember risk model given by Eq. (1) - Eq. (7) is applied to the Ginninderry region to identify the ember risk across the site. For computational purposes, the region is discretised into 0.0001 arc second cells, that is, approximately $11 \mathrm{~m} \times 11 \mathrm{~m}$. In the next section, the data used to identify $\rho_{\mathrm{EF}}$, including the VLS correction, is summarised. 

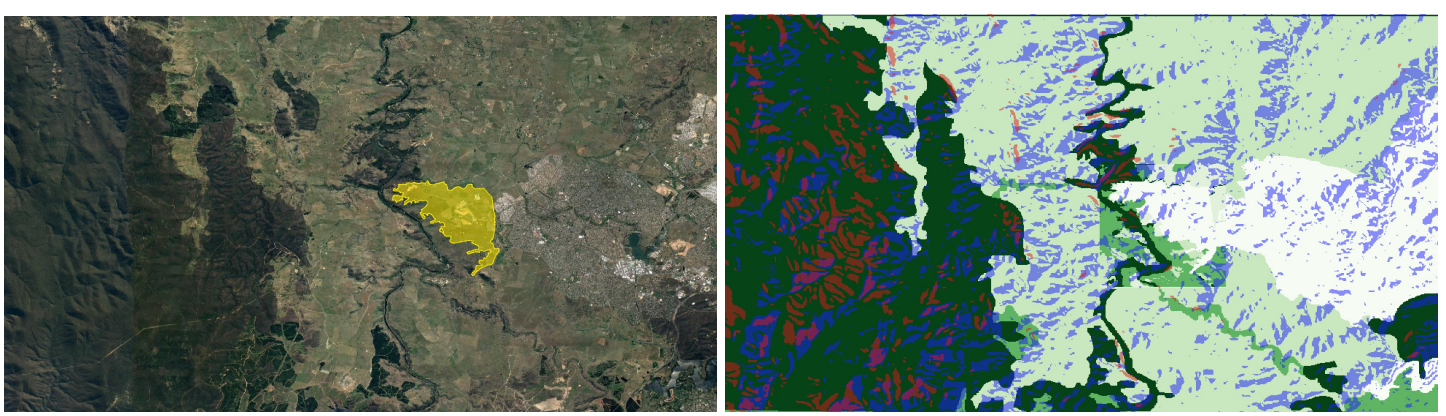

Figure 1. The site of the proposed development is indicated by the yellow polygon, shown overlaying satellite imagery of the region. The right hand figure shows the assumed fuel load for the region. Darker greens correspond to higher fuel loads. Forested areas have an assumed fuel load of $25 \mathrm{t} / \mathrm{ha}$, shrubland and woodland areas $15 \mathrm{t} / \mathrm{ha}$, mixed grassland-woodland areas $7 \mathrm{t} / \mathrm{ha}$, grasslands $4.5 \mathrm{t} / \mathrm{ha}$, and urban areas (proposed or current) $1 \mathrm{t} / \mathrm{ha}$. Areas satisfying the aspect (blue) and slope (red) requirements for VLS for a north-westerly wind are shown overlaying the assumed fuel load for the region.

\section{DATA}

The general region of interest, including Ginninderry, is shown in Fig. 1. Detailed vegetation classifications for the area immediately surrounding the proposed development were obtained from EcoLogical Australia (2014). The vegetation classification of EcoLogical Australia (2014) was manually digitised using QGIS (v2.14) and supplemented with broad classifications taken from a Google Earth image of the region. The assumed fuel load distribution $L$ is shown in Fig. 1.

The slope and aspect information is determined from the Geoscience Australia hydrologically corrected 1 arc second digital elevation model ANZCW0703014615 for the region using standard techniques in QGIS. Fig. 1 shows areas prone to $\operatorname{VLS}(\chi=1)$ for a northwesterly wind $\left(\theta=135^{\circ}\right)$.

\section{Results ANd Discussion}

The potential ember load for Ginninderry is determined for a northwesterly wind of $15 \mathrm{~m} / \mathrm{s}$. North-westerly winds are associated with dangerous fire activity in the region, and as well as being a focus of Thurston et al.'s (2014) study, a $15 \mathrm{~m} / \mathrm{s}$ wind speed is consistent with a high fire $\mathrm{d}$ anger. The relative ember risk across the proposed development is shown in Fig. 2. The ember risk is observed to be non-uniform across the region, with the northern and western fringes being of substantially higher risk than central or eastern areas of the proposed development. The ember load model provides a measure of the relative risk for an area, rather than an absolute measure. However, comparisons can be made with the results of the Hastings Bushfire case study given in Roberts et al. (2017). In January 2015 the Mornington Peninsula, Victoria, experienced their worst bushfire in a decade. Fire burnt through sections of the Warringine Park (Coastal Section) resulting in damage to 32 properties, although no houses were destroyed. Post-fire analysis determined that all damage was the result of ember attack, rather than radiant heat or direct flame contact (Terramatrix, 2 015). Fig. 2 shows the ember load for the proposed development, rescaled as multiples of the maximum ember load calculated for the Hastings Bushfire case s tudy. That is, the maximum ember load calculated for any cell within a damaged property is used to scale the calculated ember load for the Ginninderry region. The potential ember load within the development ranges from 13 to 115 times the Hastings maximum. This result implies that, in the absence of significant resilience to ember attack, property damage can be expected due to ember attack in the event of a large bushfire. However, further research, in particular improvements to the estimation of the input parameters, is required before this result can be considered definitive. Post-impact d ata is also required to validate the model.

AS3959 stipulates that for buildings more than $100 \mathrm{~m}$ from bush fire prone vegetation, no special construction requirements are required, although 'homewoners are encouraged to provide basic measures such as suitable window screening and gutter guards to minimise the impacts of ember attack (as embers can travel distances greater than 100 metres)' (NSW Rural Fire Service, 2012). As evident in Fig. 3, which shows the proximity of areas within the proposed development to vegetation (excluding grasslands), many areas at risk of ember attack fall beyond the $100 \mathrm{~m}$ mark and therefore are not required under AS3959 to have any special resilience to embers. 

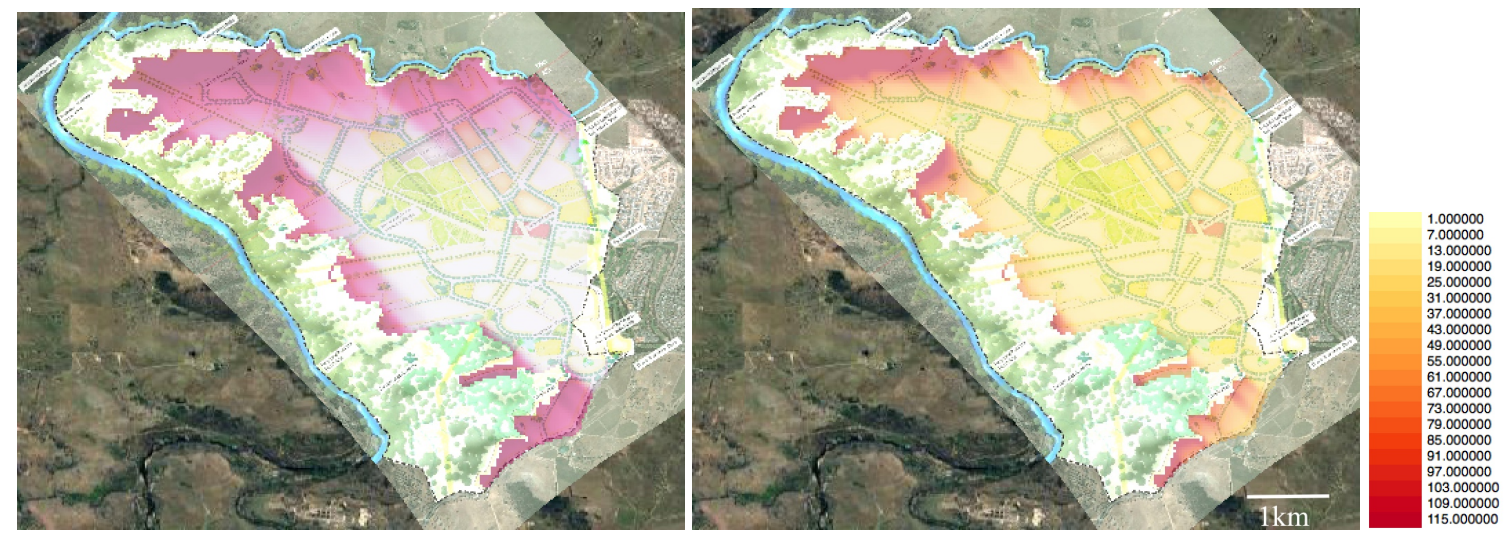

Figure 2. Ember risk for the proposed Ginninderry development is shown for two scalings. On the left, the relative ember load is shown using a log scale with darker colours corresponding to higher risk, and lighter colours to lower risk. On the right, the ember load is scaled against the maximum ember load calculated for properties damaged in the Hastings Bushfire. The minimum ember load for the proposed development, relative to the Hastings scale, is 13 times, with the maximum being 115 times.

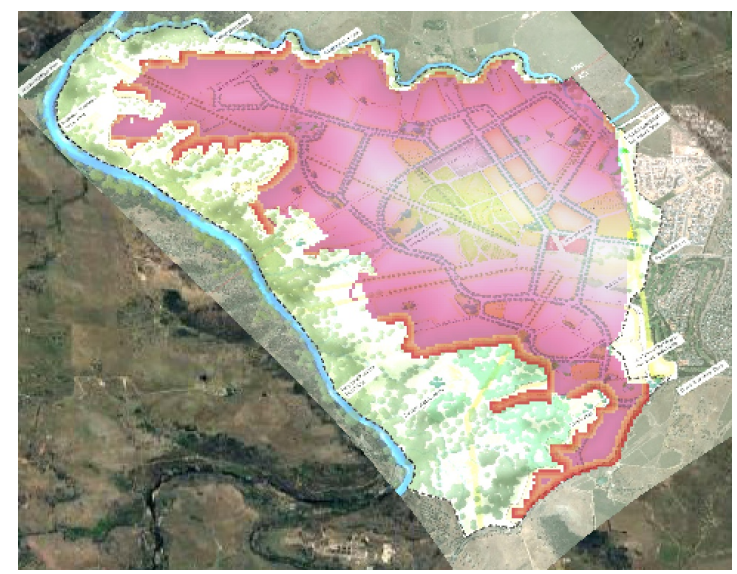

Figure 3. Proximity of areas within the proposed development to vegetation (fuel load $\geq 7 \mathrm{t} / \mathrm{ha}$ ). Areas within $100 \mathrm{~m}$ of vegetation are shown with a red - yellow colour scheme. Areas greater than $100 \mathrm{~m}$ from vegetation are shown with a purple colour scheme, with lighter colours corresponding to greater distances.

\section{Conclusion}

We have considered the effect that ember attack has on the level of bushfire risk across the Ginninderry region to the west of the ACT. Due to limitations in the current understanding of ember processes, a number of assumptions and simplifications have been necessary. Changes to these assumptions would affect the results obtained. Nevertheless, these assumptions enable us to present a proof-of-concept, despite the limitations in public data on ember impacts and transport. Further scrutiny and refinement of these assumptions will be a necessary step towards adoption of an ember load measure of bushfire risk such as has been presented.

Although the assessment of probable ember attack was underpinned by a number of assumptions, the results indicated the potential impact that embers could have on the region. Most importantly, the pattern of likely ember impact formed quite a different picture of building vulnerability than that provided by AS3959, which basically assigns building construction standards based on distance from vegetation. In contrast, the ember load model showed a strong directional effect and indicated that embers could impact structures well into parts of the region not normally assessed as vulnerable. The results presented will be refined in further work and as more data becomes available to better calibrate the ember load model. It is expected that the ember load model has the potential to provide more information to inform decisions regarding construction standard requirements. 
M. E. Roberts et al. Incorporating ember attack in bushfire risk assessment

\section{REFERENCES}

Albini, F. A. (1983). Transport of firebrands by line thermals. Combustion Science and Technology 32, 277 288.

Antheniena, R. A., S. D. Tseb, and A. C. Fernandez-Pello (2006). On the trajectories of embers initially elevated or lofted by small scale ground fire plumes in high winds. Fire Safety Journal, 349 - 363.

Blanchi, R. M., J. E. Leonard, and R. H. Leicester (2006). Bushfire risk at the rural/urban interface.

Cohen, J. P. (2001, August). A site-specific approach for assessing the fire risk to structures at the wildland/urban interface. pp. 1-5.

Cruz, M. G., A. L. Sullivan, J. S. Gould, N. C. Sims, A. J. Bannister, J. J. Hollis, and R. J. Hurley (2012). Anatomy of a catstrophic wildfire: The Black Saturday Kilmore East fire in Victoria, Australia. Forest ecology and management 284, $269-285$.

EcoLogical Australia (2014, 29 September). The west belonnen project bushfire management strategy. Technical report, EcoLogical Australia.

Ellis, P. F. (2003, October). Spotting and firebrand behaviour in dry eucalypt forest and the implications for fuel management in relation to fire suppression and to "ember" (firebrand) attack on houses. In $3 r d$ International Wildland Fire Conference, Sydney.

Haynes, K., J. Handmer, J. McAneney, A. Tibbits, and L. Coates (2010). Australian bushfire fatalities 1900 - 2008: exploring trends in relation to the 'prepare, stay and defend or leave early' policy. Environmental Science and Policy 13, 185 - 194.

Manzello, S. L., A. Maranghides, W. E. Mell, T. G. Cleary, and J. C. Yang (2006). Firebrand production from burning vegetation. In D. X. Viegas (Ed.), V Interational Conference on Forest Fire Research.

McLennan, J., G. Elliott, and M. Omodei (2012). Householder decision-making under imminent wildfire threat: stay and defend or leave? International Journal of Wildland Fire 21(7), 915.

NSW Rural Fire Service (2012). BAL risk assessment application kit new dwellings and alterations and additions to existing dwellings. Technical report, NSW Rural Fire Service.

Roberts, M. E., A. A. Rawlinson, and Z. Wang (submitted 2017). Ember risk modelling for improved bushfire risk management in the peri-urban fringes. Submitted 28 Aug 2017.

Sharples, J., R. McRae, and S. Wilkes (2012). Wind-terrain effects on the propagation of large wildfires in rugged terrain: Fire channelling. International Journal of Wildland Fire.

Standards Australia (2009). AS 3959, Australian Standard for construction of buildings in bushfire prone areas. Technical report, Standards Australia.

Tarifa, C., P. del Notario, and F. Moreno (1965). On the flight paths and lifetimes of burning particles of wood. Proceedings of the Combustion Institute 10, 1021-1037.

Terramatrix (2015). Hastings Bushfire Case Study Wanningine Park (Coasal Section). Technical report, Mornington Peninsula Shire and CFA.

Thurston, W., J. D. Kepert, K. J. Tory, and R. J. B. Fawcett (2017). The contribution of turbulent plume dynamics to long-range spotting. International Journal of Wildland Fire 26, 317 - 330.

Thurston, W., K. J. Tory, J. D. Kepert, and R. J. B. Fawcett (2014, September). The effects of fire-plume dynamics on the lateral and longitudinal spread of long-range spotting. In Proceedings of the Research Forum at the Bushfire and Natural Hazards CRC \& AFAC conference, Wellington.

Tolhurst, K. G. and K. A. Howlett (2003, July). House ignition likelihood index - an hazard assessment method for land managers in the wildland-urban interface. pp. 1-11.

Wilson, A. A. G. (1988). A simple device for calculating the probability of a house surviving a bushfire. Australian Forestry 51(2), 119-123.

Woycheese, J. P., P. J. Pagni, and D. Liepmann (1999). Brand propagation from large-scale fires. J. of Fire Prot. Engr. 10(2), 32-44. 